\title{
Hot-spring bathing of wild monkeys in Shiga-Heights: origin and propagation of a cultural behavior
}

\author{
Tetsuro Matsuzawa ${ }^{1,2,3}$
}

Published online: 17 April 2018

(c) Japan Monkey Centre and Springer Japan KK, part of Springer Nature 2018

\section{The rise of primatology in Japan}

This paper aims to introduce a historical summary of hotspring bathing by wild Japanese monkeys of the Jigokudani area, Shiga-Heights, Nagano Prefecture, Japan. Japanese monkeys (Macaca fuscata), often called snow monkeys, of Jigokudani developed hot-spring bathing behavior right after provisioning began in 1962 (Fig. 1). This behavior continues to gain increasing attention from people outside of Japan and the foreign media, but without a proper understanding of the origin of this behavior. This is mainly due to the lack of academic literature written on the topic, even in Japanese.

I have studied the wild Japanese monkeys in ShigaHeights (Matsuzawa et al. 1983; Wada and Matsuzawa 1986). In fact, I began my study of wild Japanese monkeys before my first encounter with the, now famous, female chimpanzee named Ai on November 10, 1977. I became familiar with the Shiga-Heights site between February 14 and 19, 1977, right after getting the position of assistant professor at the Primate Research Institute on December 1, 1976. I have even taken a hot bath with wild monkeys sharing the same hot tub. In this sense, I might be thought of as qualified to talk about the history of this fascinating behavior through my direct experience with the hot-spring bathing monkeys. I want to summarize the history of the hot-spring monkeys based on three important publications written in Japanese (Hara 1971; Wada 1979; Jigokudani Monkey Park 2014).

Let me start by introducing the rise of primatology in Japan. It was on December 3, 1948, that Kinji Imanishi (1902-1992) first visited Koshima Island to see the wild

Tetsuro Matsuzawa

matsuzawa.tetsuro.8w@kyoto-u.ac.jp

Institute for Advanced Study, Kyoto University, Kyoto, Japan

2 Primate Research Institute, Kyoto University, Inuyama, Japan

Japan Monkey Centre, Inuyama, Japan

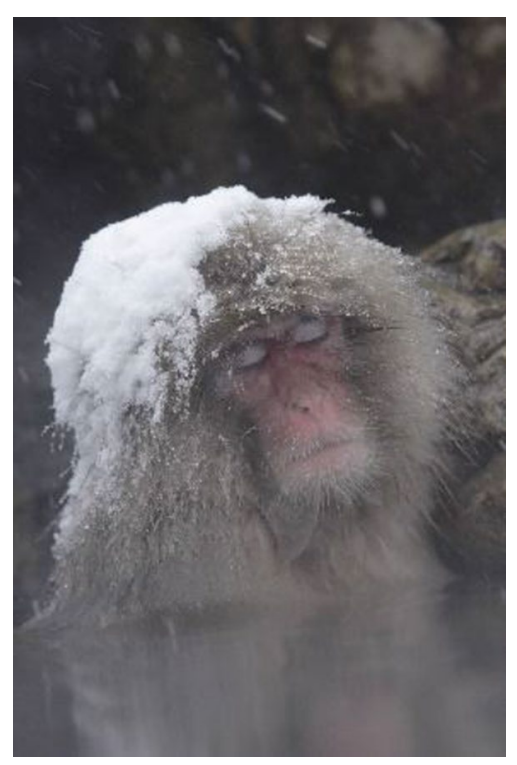

Fig. 1 A snow monkey in the hot spring at Jigokudani, ShigaHeights, Nagano Prefecture, Japan (photo by Toshio Hagiwara)

Japanese monkeys. He was accompanied by two undergraduate students, Jun'ichiro Itani and Shunzo Kawamura. This was the day that Japanese primatology truly began (Matsuzawa 2015; Matsuzawa and McGrew 2008).

Itani graduated from Kyoto University in 1951. Under the supervision of Imanishi, Itani got a job at the Nagoya Railway Company, hired especially to participate in a new endeavor-establishing the Japan Monkey Centre (JMC), then as now, a museum and zoo of nonhuman primates (see http://www.japanmonkeycentre.org). The JMC was founded on October 17, 1956.

During this period, Itani published his first book, entitled "The Monkeys of Takasakiyama", in Japanese, in 1954. His book won a literary prize - the Mainichi Newspaper Publishing Book Award of 1955. According to Itani's account of his 7 years of research, from 1948 to 1955 , the students 
in Imanishi's research group together spent a total of 1383 days in the forest to observe wild Japanese monkeys at 19 different sites across Japan: from Shimokita Peninsula in the north to Yakushima Island in the south (excluding ShigaHeights - as yet unstudied). This primatological survey of wild Japanese monkeys garnered wide attention among the general public in 1950's Japan.

\section{Provisioning of Jigokudani monkeys at Shiga-Heights}

Shogo Hara was the key person. Mr. Hara was an employee of the Nagano Railway Company. In between his paid work at Yudanaka station, he would explore Jigokudani and the other mountains and valleys of Shiga-Heights. He first set foot in the Jigokudani area in July 1957 and happened upon a troop of more than 100 monkeys. Incidentally, "Jigoku" means "hell", in Japanese, and "Dani" or "Tani" means "valley". Therefore, "Jigokudani" means "Valley of hell" or "Death valley", so called because the smell of sulfurous hot springs is always hanging in the air. Hara got the idea of provisioning the monkeys in order to show them to the public. He submitted a proposal for this provisioning to the Nagano Railway Company in September 1957.

In 1958, Yoshio Furuya, then a Kyoto University researcher, joined the survey of Jigokudani monkeys being carried out by Mr. Hara. Mr. Furuya was one of Imanishi's students and an old friend of Mr. Hara; they both graduated from the same secondary school and high school together.

Furuya took the role of forming a bridge between the young scholars of Kyoto University and the monkeys of Jigokudani. In March of 1960, Shigeru Azuma, Yukimaru Sugiyama, and Kazuo Wada first visited the wild monkeys at Jigokudani. They were followed by Akira Suzuki in 1962 (Suzuki 1965). Wada wrote a book in Japanese on the ecology of the wild monkeys of Shiga-Heights. He classified the troops and gave names to each, such as Shiga A, B, and C. The Jigokudani troop is called Shiga A. Suzuki wrote the first paper in English on the hot-spring bathing monkeys of Jigokudani (Suzuki 1965). His paper has been the only source of information available for non-Japanese readers for many years: foreign readers recognized the unique behavior for the first time upon seeing the photos in his paper.

Ski resorts were established at Shiga-Heights during the 1950s. The wild monkeys were thereafter pushed out, and chased away, from the newly developed human area. The monkeys become a nuisance; for example, some ate fruit in orchards. The provisioning of these monkeys was carried out both to prevent agricultural damage and to facilitate tourism-visitors coming to see the monkeys. In Jigokudani, there used to be a Japanese inn named Korakukan. The landlady was named Harue Takefushi. Mr. Hara, together

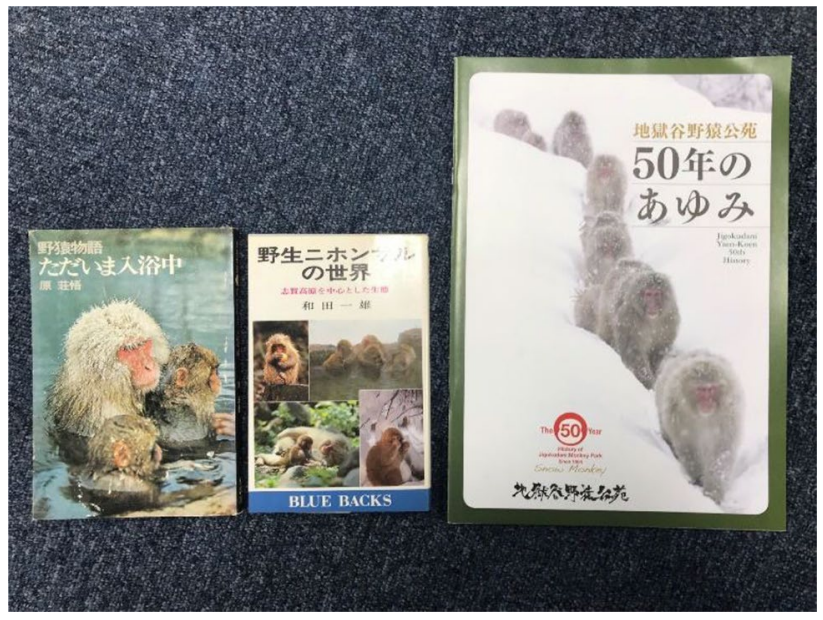

Fig. 2 The three books on Jigokudani monkeys published in Japanese. From left to right: Hara (1971), Wada (1979), and Jigokudani Monkey Park (2014) (photo by Tetsuro Matsuzawa)

with Ms. Takefushi and the Nagano Railway Alpine Club, succeeded in getting the monkeys to accept provisioned food. The first success in provisioning was achieved on September 12, 1962 (Hara 1971). It occurred near Korakukan Inn, located at an altitude of $850 \mathrm{~m}$. Hara used apples to attract the monkeys; they took apples to eat that had been strewn on the ground by humans. Thus, provisioning took 5 years to become established following the first encounter with the monkeys at Jigokudani. At that time, Shiga A troop (Jigokudani troop) numbered 23 individuals (Wada 1979).

\section{Young monkeys enter the hot spring}

After provisioning was successful, the wild monkeys began to visit the Korakukan area often. Korakukan Inn had its own hot bath outdoors - it is a major part of Japanese culture that people love to soak in hot baths in the open air. Next, the provisioned monkeys started playing with the water in the hot bath, then actually climbed into it. The question is which monkey initiated this unique behavior.

There are three Japanese publications relevant to this matter: Hara (1971), Wada (1979), and Jigokudani Monkey Park (2014). I read all three in order to compare their accounts (Fig. 2). According to the Jigokudani Monkey Park (2014), the first recorded incidence of monkeys hot-bathing was in the winter of 1962 by Tomio Yamada, a policeman for Nagano Prefecture, who happened to successfully take a photograph of the hot-bathing monkeys (Fig. 3). This appeared in the Asahi Shimbun, a national newspaper, however, on June 29th 1964 (not in 1962). For the purpose of writing this paper, I attempted to contact Mr. Yamada and succeeded. He kindly provided me with the first photo of 


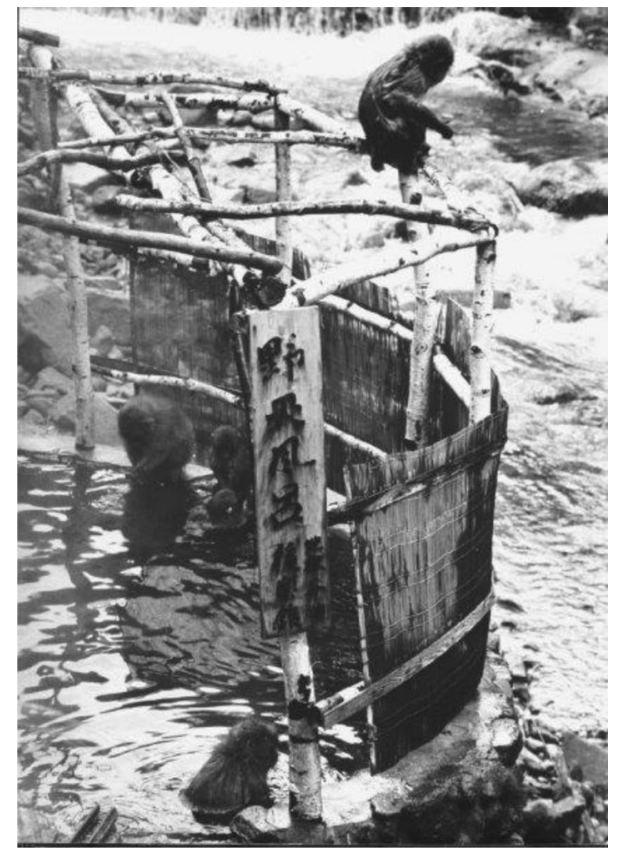

Fig. 3 The first photo of hot-bathing monkeys, taken in the winter of 1963 to 1964. The monkeys are in the hot-bath tub intended for human use in Korakukan Inn (photo by Tomio Yamada)

monkeys hot-bathing, in the bathing tub for humans in Korakukan Inn, taken in the winter between November 1963 and March 1964.

According to Hara's writing (Hara 1971), he witnessed the first case of monkeys hot-spring bathing one day in January 1963. He wrote his book between January and February, 1971 - almost 9 years after the date of his original observation. Therefore, writing his account a good while after the fact, Hara was not able to pinpoint the exact date. His observation is recounted as follows. A 2-year-old monkey put its fingers into the water of the hot-spring bath. This monkey then moved its fingers around in the hot spring. The movement of its hand caused tiny bubbles to rise to the surface of the water. The monkey then seemed to be trying to catch the tiny bubbles. Then the monkey stopped moving its fingers and simply kept them still in the hot water. Then, gradually, the monkey immersed both hands wholly in the water, and then its forearms, and remained quiet and still, without movement. Then the monkey put a foot into the water too. To Hara, the monkey appeared to enjoy the heat of the thermal water. Finally, the monkey put its other foot into the hot water and then its entire body. Now, the monkey was immersed up to the neck; its whole body below the neck was in the hot water-just like when humans in Japan enjoy an 'onsen' or hot bath.

Hara could not relate the identity of this hot-bathing monkey. Because the episode happened only a few months after the first success in provisioning, Hara was not yet able to identify each monkey within the troop reliably. However, it is relatively easy to estimate the age of the individualaround 2 years old. Later in his book, Hara speculates that the monkey must be one of three born in 1960: thus two-anda-half years old. If this is so, the monkey was either Mejiro (female), Kiku (female), or Popeye (male).

Let me continue introducing Hara's description of the hotbathing monkeys. Once inside the water, the young monkeys did not move into the center, but continued to cling to the rock wall of the bath. Later, some of them began to venture towards the center, and even ducked underneath the water. Monkeys naturally possess the ability to swim. Monkeys swim just like we do, using all four limbs. Next, the young monkeys started to play together in the hot water, pulling on each other's arms and legs and jumping on top of their heads, etc. The adults would watch those young monkeys, he recounts, but did not try to get into the hot spring. The hot-spring bathing behavior had soon spread to slightly older monkeys, of 3-4 years old. Then, the following year, 1964, the mothers of these young monkeys also began to hot-bathe. The males that were adults at the time never entered the hot spring. However, the males that were in the hot spring with their mothers as youngsters, continued to hot-bathe as adults. Thus, Hara became convinced that the behavior was culturally propagated.

Wada based his book (1979) on a series of short articles he contributed to the Shinano-Mainichi Shimbun, a newspaper, during 1976-1977. According to Wada, he observed the first case of a monkey hot-spring bathing on February 6, 1963. He claims that he happened to witness it as follows. The monkeys of Shiga A troop were eating the apples routinely provisioned to them in an area near Korakukan Inn. While the apples were being thrown onto the ground, one of them happened to land in the hot spring, and remained floating there. The hot-spring bath was $2.5 \mathrm{~m}$ wide by $4 \mathrm{~m}$ long, and $0.5 \mathrm{~m}$ deep. The apple was bobbing in the center of the bath. First, a 1-year-old monkey tried to get at the apple, but failed initially. He put both his arms into the hot water. He continued to reach down, deeper and deeper. Gradually, he got into the hot water. Eventually, he succeeded in getting the apple and moved back onto the edge of the hot spring. About 5 min later, the same young monkey got into the hot spring even though there was now no apple there. He immersed himself in the hot water and lay on his back floating in the water, or simply sat in the water, quietly. Nearby were three young monkeys, all aged 2-3 years. The mother of the young monkey that reached the bobbing apple was also there; Wada identified her as "Muku". According to the record of the family lineage made by Hara and his successor, Eishi Tokida, Muku had a male infant named "Shiga", born in early 1962. "Shiga" must be the male monkey featured in Wada's account.

According to Wada (1979), within several months, two monkeys aged 2 years and two 3-year-olds had started 
hot-spring bathing. Within a year, the behavior had spread to the 4-year-olds. Wada also mentioned that adult males immigrating from other troops never tried to enter the hot spring. However, by that point, all the females practiced hot-spring bathing. There was no incidence of hot-spring bathing before provisioning began. The hot-spring bathing followed on from the provisioning and it originated among young monkeys. The behavior spread from the younger to the older generation.

Suzuki (1965) dates his first observation of a monkey hotspring bathing to February 11, 1963. He reported that he saw four young monkeys, aged 1-3 years, get into the hot spring. Putting everything together, there were four young monkeys that started to hot-bathe, two males and two females, aged from 1 to 2-and-a-half years old, during that winter between December 1962 and February 1963. According to the available literature, in my opinion it is fair to say that one of these four candidate monkeys initiated the new hot-spring bathing behavior. Afterwards, the other young monkeys followed the lead and also carried out the behavior. This was followed by the adult females. Adult males arriving from other troops never attempted this behavior.

After the initial observations carried out in the early phase, by Hara (1971), Wada (1964, 1979), and Suzuki (1965), for many years there was only a single paper published in English (Zhang et al. 2007). This research was completed by Zhang Peng, a Chinese researcher, at that time a student of the Primate Research Institute of Kyoto University, with his supervisor, Kunio Watanabe, and an on-site collaborator, Eishi Tokida. Their paper gives a summary of data across 24 years, from 1980 to 2003 . Among 114 female monkeys, $31 \%$ of them practiced hot-spring bathing, in short, about one-third of the females. Females and young monkeys apparently loved to hot-spring bathe, but few adult males. Hot-spring bathing is more frequent in winter and less frequent in summer. Therefore, they inferred that the behavior helps with thermoregulation.

Sayuri Takeshita and her colleagues (Takeshita et al. 2018) showed that hot-spring bathing has a stress reduction effect in adult females (Fig. 3).

\section{Snow monkeys of Shiga-Heights and tourism}

Jigokudani Monkey Park was founded in 1964. The park was supported financially by local people and by the Nagano Railway Company. The first director was Mr. Hara. Hara was succeeded by Eishi Tokida, next was Haruo Takefushi, and then Toshio Hagiwara (Jigokudani Monkey Park 2014).

In November 1967, the park staff created a new hot spring bath, separate from the inn, for monkeys only. This is the same bath the monkeys use today. This was done for hygiene reasons, to ensure that humans and monkeys did not bathe together. Humans never use the monkey park hot-bath tub, but the monkeys do still occasionally use the original human hot-bath tub even today. The source of the hot water is a natural thermal spring, about $300 \mathrm{~m}$ upstream. This natural hot spring, about $40{ }^{\circ} \mathrm{C}$ in temperature, is also used by the monkeys. There has been a variety of research on Shiga A troop, including my own on taste aversion learning in wild monkeys (Matsuzawa et al. 1983) and a series of studies led by Ichiro Tanaka on louse-egg grooming techniques (Tanaka and Takefushi 1993). The young researchers of the University of Tokyo and Kyoto University continue to study Shiga A troop in Jigokudani.

In 1969, the park stopped selling tourists food to give to the monkeys. Previously, they had been allowed to throw food to the monkeys, but from that point onwards it has been forbidden. There are no monkeys or apes native to North America or Europe. For the people of these regions, snow monkeys in the wild are a fascinating novelty, even more so when those monkeys practice hot-spring bathing-uniquely the monkeys of Shiga-Heights. The beginning of the growth in popularity of these monkeys outside Japan can be traced to an issue of LIFE magazine that came out on January 30, 1970. The cover image featured the hot-spring bathing monkeys of Jigokudani. In 1998, the Winter Olympic Games were held in Nagano (Nagano Prefecture, Japan) and that event further boosted the monkeys' worldwide fame. In 2006, a photo taken by a member of the park staff, Toshio Hagiwara (Fig. 4), received the Grand Prize in Nature's Best Photography Windland Smith Rice International Award. In 2007, the Michelin Green Guide Japan awarded a prestigious star to the Jigokudani Monkey Park. According to park records, the number of visitors in the 2013 fiscal year totaled 152,000. Among them, 42,000 were non-Japanese (about 28\%) (Fig. 5).

During the course of researching this article, I visited the park, on March 26, 2018. My previous visit was back in

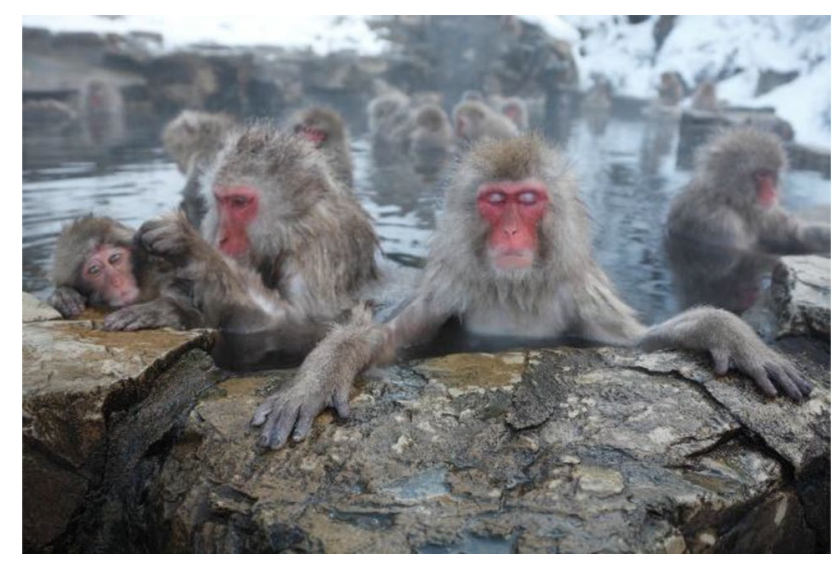

Fig. 4 The monkeys of Jigokudani in the hot spring. Takeshita et al. (2018) reported the stress-reduction effect of hot-bathing in addition to thermoregulation (photo by Toshio Hagiwara) 


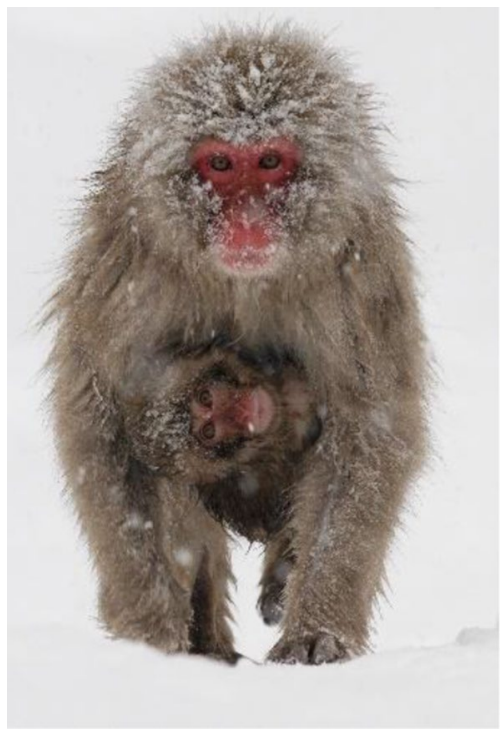

Fig. 5 Japanese monkeys in Jigokudani. This is a photograph taken by Toshio Hagiwara, for which he received the Grand Prize in Nature's Best Photography Windland Smith Rice International Award in 2006. The photo is of a young female, of 6-7 years old, with her infant, and was taken on January 12, 2005

November 8, 2009, so there was a decade interval between visits. When I visited in 2009 , the practice of the park staff was to regularly throw wheat into the hot bath, so that the monkeys climbed into the hot spring to get at this food. The current director, Mr. Hagiwara, stopped this kind of touristattracting activity about 4 years ago. Therefore, currently the monkeys certainly are not "forced" into the hot spring. According to Mr. Hagiwara, the number of visitors in 2017 was about 240,000 , and about 95,000 of these were nonJapanese (about 40\%).

The park staff provision the monkeys with grains of wheat, four times a day, between 09:00 and 16:00 h. Shiga A troop is made up of about 160 monkeys. About 40 of them (around 25\%), carry out the practice of hot-spring bathing. The day of my visit was a warm spring day. None of the monkeys climbed into the hot spring, but some enjoyed sitting in the sunshine on the rocks that make up the edge of the hot spring. They groomed each other. After the final provisioning session that day, in the late afternoon, they returned gradually, a few at a time, to the surrounding mountainside.

Visitors have to walk about $1.6 \mathrm{~km}$ from the car parking area to reach the monkey park. Foreign visitors, especially, enjoy the forest walk among tall 'Sugi', Japanese cedar (Cryptomeria japnonica), and 'Hinoki', Japanese cypress trees (Chamaecyparis obtusa), tree species native to Japan. In the period from April to June, infants will be born; Mr. Hagiwara expects there to be 20 newborns in 2018. I happened to see two Japanese serow (Capricornis crispus), a type of goat-antelope, on the mountainside near the monkeys. If you are lucky, on your visit, you can see serow and monkeys; you can enjoy the beautiful wildlife of Shiga-Heights while there to watch the hot-spring bathing monkeys.

Acknowledgements I am most grateful to Mr. Toshio Hagiwara, the Director of Jigokudani Monkey Park. He kindly sent me an invaluable publication and information on the hot-spring bathing monkeys. $\mathrm{He}$ also gave me the opportunity to conduct an on-site interview about the current situation regarding the monkeys, and permitted to me to use his excellent photos. Thanks are due to Mr. Tomio Yamada who took the first photo of hot-spring bathing monkeys and kindly allowed me to reproduce it here. I also appreciate the efforts of Prof. Ichiro Tanaka, who has dedicatedly studied the monkeys of Jigokudani (Shiga A troop) for many years. He provided me with general information about the monkeys and formed a bridge between Jigokudani Monkey Park and me. Thanks are also due to Dr. Sayuri Takeshita and her colleagues who contributed an article on the hot-bathing monkeys to Primates. This fascinating manuscript convinced me of the necessity of preparing an article to introduce background information on the hot-spring bathing monkeys. This leads us inevitably to understand the three most important aspects of cultural behavior in wild monkeys: emergence, propagation, and modification. For further information on Jigokudani Monkey Park, please visit their homepage: http://en.jigokudani-yaenk oen.co.jp/. Financial support for preparing this manuscript came from MEXT-JSPS Grants \#16H06283; LGP-U04, and the Japan Society for the Promotion of Science (JSPS) Core-to-Core Program CCSN to the author. I also thank Dr. Claire Watson for editing the English text.

\section{References}

Hara S (1971) "Yaen-monogatari” (A story about wild Japanese monkeys). Shinanoji, Nagano (in Japanese)

Jigokudani Monkey Park (2014) 50 years record of Jigokudani Monkey Park. Jigokudani Monkey Park, Nagano (in Japanese)

Matsuzawa T (2015) Sweet-potato washing revisited: 50th anniversary of the primates article. Primates 56:285-287

Matsuzawa T, McGrew W (2008) Kinji Imanishi and 60 years of Japanese primatology. Curr Biol 18:R587-R591

Matsuzawa T, Hasegawa Y, Gotoh S, Wada K (1983) One-trial longlasting food-aversion learning in wild Japanese monkeys (Macaca fuscata). Behav Neural Biol 39:155-159

Suzuki A (1965) An ecological study of wild Japanese monkeys in snowy areas: focused on their food habits. Primates 6:31-72

Takeshita RSC, Bercovitch FB, Kinoshita K, Huffman MA (2018) Beneficial effect of hot spring bathing on stress levels in Japanese macaques. Primates. https://doi.org/10.1007/s10329-018-0655-x

Tanaka I, Takefushi H (1993) Elimination of external parasites (lice) is the primary function of grooming in free-ranging Japanese macaques. Anthropol Sci 101:187-193

Wada K (1964) Some observations on the life of monkeys in the snow district of Japan. Physiol Ecol 12:151-174 (in Japanese)

Wada K (1979) The world of wild Japanese monkeys: focusing on the ecology in Shiga-Heights. Kodansha, Tokyo (in Japanese)

Wada K, Matsuzawa T (1986) A new approach to evaluating troop deployment in wild Japanese monkeys. Int J Primatol 7:1-14

Zhang P, Watanabe K, Tokida E (2007) Habitual hot-spring bathing by a group of Japanese macaques (Macaca fuscata) in their natural habitat. Am J Primatol 69:1425-1430 